\title{
Avaliação de variáveis que influenciam a hidrólise enzimática da caseína do leite de cabra Moxotó
}

\author{
Tatiana Barros Ferreira Lira(1), Vilma Sobral Bezerra(1), Flávio de Oliveira Silva(1), \\ Giselle Maria Pereira Dias ${ }^{(2)}$, José Luiz de Lima Filho(2), Tatiana Souza Porto(1) \\ e Ana Lúcia Figueiredo Porto(1)
}

\begin{abstract}
(1)Universidade Federal Rural de Pernambuco, Avenida Dom Manoel de Medeiros, s/nº, Dois Irmãos, CEP 52171-900 Recife, PE. E-mail: taty.vet@gmail.com, villsb@yahoo.com.br, foliveirasilva@gmail.com, portots@yahoo.com.br, analuporto@yahoo.com.br (2)Universidade Federal de Pernambuco, Avenida Prof. Moraes Rêgo, s/no, Cidade Universitária, CEP $50670-901$ Recife, PE. E-mail: diasgmp@yahoo.com.br, joseluiz60@gmail.com
\end{abstract}

\begin{abstract}
Resumo - O objetivo deste trabalho foi avaliar os efeitos da temperatura, $\mathrm{pH}$, relação enzima:substrato (E:S) e tempo de reação sobre a hidrólise enzimática da caseína do leite de cabra Moxotó, com uso de diferentes enzimas proteolíticas. A hidrólise enzimática da caseína caprina foi realizada com uso de tripsina, pepsina e papaína. Para cada enzima, foram utilizados dois níveis de cada variável, na avaliação de seus efeitos sobre a hidrólise da caseína, em um fatorial completo $2^{4}$. Os produtos da hidrólise foram visualizados em eletroforese SDS-PAGE. O melhor valor do grau de hidrólise com a enzima papaína foi obtido em pH 6,5, E:S de 1:150 e 5 horas de hidrólise a $50^{\circ} \mathrm{C}(28,17 \%)$; com a tripsina, em pH 8,5, E:S de $1: 150$ e 5 horas a $40^{\circ} \mathrm{C}(29,55 \%)$; e com a pepsina, em pH 3,0, E:S de 1:100 e 5 horas a $40^{\circ} \mathrm{C}(38,27 \%)$. A hidrólise da caseína caprina é influenciada positivamente pelo $\mathrm{pH}$ e tempo de hidrólise, com o uso da pepsina. Foram observadas interações significativas antagônicas entre $\mathrm{pH}$ e relação E:S, com o uso da tripsina; e entre pH, temperatura e tempo de hidrólise, com o uso da papaína. A pepsina apresenta elevada eficiência na hidrólise de $\alpha_{\mathrm{s} 1}, \beta$ e $\kappa$-caseína, evidenciada por hidrolisados com massa molar abaixo de 14,4 kDa.
\end{abstract}

Termos para indexação: Capra hircus, leite de cabra, papaína, pepsina, proteólise, tripsina.

\section{Evaluation of the variables that influence the enzymatic hydrolysis of Moxotó goat's milk casein}

\begin{abstract}
The aim of this work was to evaluate the effects of temperature, $\mathrm{pH}$, enzyme:substrate ratio (E:S), and reaction time on the enzymatic hydrolysis of Moxotó breed goat's milk casein, using different proteolytic enzymes. Enzymatic hydrolysis of the capric casein was performed using trypsin, pepsin and papain. For each enzyme, two levels of the variables were used to assess their effects on the hydrolysis of casein, using a full factorial design $\left(2^{4}\right)$. The hydrolysis products were visualized on SDS-PAGE. The best hydrolysis degree using papain were at $\mathrm{pH} 6.5, \mathrm{E}: \mathrm{S}$ of $1: 150$ and 5 hours of hydrolysis at $50^{\circ} \mathrm{C}(28.17 \%)$; for trypsin, at $\mathrm{pH} 8.5$, E:S of $1: 150$ and 5 hours at $40^{\circ} \mathrm{C}(29.55 \%)$; and for pepsin, at $\mathrm{pH} 3.0$, E:S of $1: 100$ and 5 hours at $40^{\circ} \mathrm{C}(38.27 \%)$. Capric casein hydrolysis is affected positively by $\mathrm{pH}$ and reaction time, using pepsin. Significant antagonistic interactions were observed between $\mathrm{pH}$ and $\mathrm{E}: \mathrm{S}$, with trypsine; and between $\mathrm{pH}$, temperature and reaction time, with papain. Pepsin has high $\alpha_{\mathrm{s} 1}, \beta$ e $\kappa$-casein hydrolysis efficiency, evidenced by the molar masses below $14.4 \mathrm{kDa}$ of its products.
\end{abstract}

Index terms: Capra hircus, goat's milk, papain, pepsin, proteolysis, trypsin.

\section{Introdução}

O Brasil possui o nono maior rebanho de caprinos do mundo, do qual mais de $90 \%$ encontra-se na Região Nordeste (Rocha et al., 2007). A raça Moxotó é nativa do nordeste brasileiro e apresenta características adaptativas que permitem a sobrevivência e a reprodução em regiões semi-áridas, principalmente no período de estiagem, o que a torna um recurso genético valioso que, segundo Oliveira (2004), precisa ser conservado e melhor caracterizado.
O estudo das propriedades funcionais e nutricionais dos produtos lácteos é estratégia adequada para melhor aproveitamento do leite caprino (Santillo et al., 2009). As características peculiares do leite de cabra, do ponto de vista nutricional e social, motivam pesquisas para avaliação de aspectos produtivos e qualitativos de sua produção (Fernandes et al., 2008).

A maior digestibilidade do leite de cabra se deve à maior quantidade de ácidos graxos de cadeia curta e ao menor diâmetro dos glóbulos de gordura. Há crescente 
interesse pela utilização desse produto como alimento funcional, em consonância com a atual tendência de alimentação saudável (Olalla et al., 2009). Entre as características nutricionais benéficas do leite de cabra, destacam-se a elevada concentração de proteínas de alto valor nutritivo e a possível utilização desse leite por pessoas alérgicas ao leite de vaca (Olalla et al., 2009; Santillo et al., 2009).

As proteínas do leite estão entre os temas que despertam grande interesse científico, em razão de sua importância na nutrição e fisiologia humana. Os efeitos das proteínas do leite sobre a saúde humana podem estar relacionados à proteína intacta, aos aminoácidos da proteína totalmente digerida e aos peptídeos da proteína parcialmente hidrolisada (Michaelidou, 2008). Entre as proteínas que constituem o leite, $80 \%$ são representadas pelas caseínas e $20 \%$ pelas proteínas do soro (Olalla et al., 2009).

Leónil et al. (2000) destacam o crescente interesse tecnológico por hidrolisados enzimáticos proteicos de produtos lácteos, uma vez que a hidrólise enzimática pode contribuir para a melhoria das propriedades funcionais das proteínas, e esses produtos são fontes ricas em proteínas, cálcio, vitaminas e compostos bioativos, o que aumenta seu potencial de emprego na elaboração de alimentos e ingredientes funcionais.

A caseína apresenta elevada susceptibilidade à ação catalítica das proteases conhecidas (Carreira et al., 2003). A maioria dos peptídeos derivados da caseína que apresentam atividade biológica é produzida in vitro pelo uso de proteinases, especialmente a tripsina (Krüger, 2006; Rossini et al., 2009). A utilização de enzimas proteolíticas para hidrólise da caseína caprina, com vistas a aplicações futuras dos peptídeos, foi relatada por Trujillo et al. (1997), Cavalli et al. (2008) e Santillo et al. (2009), porém não foram encontrados relatos de estudos sobre a raça Moxotó.

O controle dos parâmetros da hidrólise enzimática das proteínas é importante para a obtenção de produtos com elevada qualidade nutricional (Biasutti, 2006). Estudos realizados por Guo et al. (2009) mostraram a importância de avaliar a temperatura, o pH, o tempo e a relação enzima-substrato durante o processo de hidrólise enzimática das proteínas do soro de leite bovino.

O grau de hidrólise é um critério quantitativo da reação de proteólise utilizado para comparar hidrolisados entre si, e é definido como a percentagem de ligações peptídicas clivadas em relação ao total deligações peptídicas (Biasutti, 2006). A hidrólise enzimática pode ser avaliada por vários métodos, entre os quais destacam-se a eletroforese em gel de poliacrilamida uni ou bidimensional, a cromatografia líquida de alta pressão em fase reversa, a eletroforese capilar e a espectrometria de massa (Krüger, 2006).

$\mathrm{O}$ objetivo deste trabalho foi avaliar o efeito da temperatura, $\mathrm{pH}$, relação enzima:substrato $(\mathrm{E}: \mathrm{S})$ e do tempo de reação sobre o grau de hidrólise da caseína do leite de cabra da raça Moxotó, com a utilização de diferentes enzimas proteolíticas.

\section{Material e Métodos}

O leite caprino da raça Moxotó foi obtido de forma higiênica, conforme procedimentos estabelecidos na Instrução Normativa №. 37 de 2000 do Ministério da Agricultura, Pecuária e Abastecimento (Brasil, 2000). $\mathrm{O}$ animal utilizado para extração do leite era proveniente do Município de Sertânia, Estado de Pernambuco, Brasil.

As amostras de leite foram congeladas imediatamente após a coleta e mantidas em nitrogênio líquido. $\mathrm{O}$ procedimento da extração da caseína foi realizado segundo Egito et al. (2006), exceto pela retirada do tolueno. O precipitado da caseína foi solubilizado com $1 \mathrm{~mol} \mathrm{~L}^{-1} \mathrm{de} \mathrm{NaOH}$, até $\mathrm{pH} 7,0$, e submetido à diálise contra água deionizada a $4^{\circ} \mathrm{C}$ por 96 horas. Após a liofilização da caseína, foram preparadas soluções que continham $2 \%$ de caseína em solução tampão fosfato $0,1 \mathrm{~mol} \mathrm{~L}^{-1}$, para hidrólise com papaína e tripsina, e em solução tampão $\mathrm{HCl}-\mathrm{KCl}$, para hidrólise com a pepsina.

O efeito das variáveis $\mathrm{pH}$, temperatura, tempo e relação enzima:substrato (E:S) sobre o grau de hidrólise $(\mathrm{GH})$ foi avaliado de acordo com o planejamento fatorial completo $\left(2^{4}\right)$, em que as variáveis foram avaliadas em dois níveis, conforme as recomendações de Bruns et al. (2006). Foram realizados 16 ensaios correspondentes às combinações entre os níveis das variáveis, com quatro repetições no ponto central. O mesmo planejamento foi realizado com utilização das enzimas tripsina (EC. 3.4.21.1), papaína (EC. 3.4.22.2) e pepsina (EC. 3.4.23.1), com diferença apenas quanto ao $\mathrm{pH}$, que é específico para cada enzima. Os parâmetros utilizados na hidrólise foram: temperatura de 40, 45 e $50^{\circ} \mathrm{C}$; tempo de hidrólise de 1, 3 e 5 horas; e relação E:S de1:150, 1:125 e 1:100.

$\mathrm{O} \mathrm{pH}$ utilizado na hidrólise da caseína foi diferente para cada enzima: papaína, 6,5, e 7,0 e 7,5; tripsina, 7,5, 8,0 e 8,5; e pepsina, 2,0, 2,5 e 3,0. As enzimas foram adquiridas da Sigma Chemical Co, St. Louis, EUA. 
A seleção das variáveis e de seus níveis foi feita de acordo com a literatura (Carreira et al., 2003; Soares et al., 2004; Guo et al., 2009; Rossini et al., 2009). A análise estatística foi realizada com o auxílio do programa Statistica 8.0 (StatSoft, 2008). Após a hidrólise, as amostras foram submetidas à agitação por 30 segundos e colocadas em banho-maria com água a $90^{\circ} \mathrm{C}$, por 15 minutos, para inativação das enzimas.

Para a determinação do grau de hidrólise das enzimas proteolíticas, utilizou-se a metodologia adaptada de Pezoa \& Salas-Mellado (1979). As amostras foram centrifugadas a $12.000 \mathrm{~g}$, durante 10 minutos. O GH foi expresso segundo a relação das quantidades de proteínas solúveis determinadas pelo método de Lowry et al. (1951) e de proteínas totais presentes no substrato (caseína), determinadas pelo método de Kjeldahl, preconizado por Horwitz (2000).

Os hidrolisados da caseína foram analisados por eletroforese SDS-PAGE conforme Laemmli (1970), em gel a $15 \%$ de concentração, e corados por Coomassie brilliant blue R-250 (Varghese \& Diwan, 1983) e corante de prata (Switzer et al., 1979). A utilização dessa metodologia se aplica à visualização dos hidrolisados proteicos com diferentes massas molares. Nas corridas eletroforéticas, foram aplicados $3 \mu \mathrm{L}$ das amostras na concentração de $1 \mu \mathrm{g} \mu \mathrm{L}^{-1}$, com exceção da amostra de caseína presente na linha 7 , na qual foi aplicada $5 \mu \mathrm{L}$. Os marcadores de baixa massa molar (GE Healthcare, Buckinghamshire, UK) usados foram fosforilase $b$ (97 kDa), albumina (66 kDa), ovoalbumina (45 kDa), anidrase carbônica (30 kDa), inibidor de tripsina $(20,1$ $\mathrm{kDa}$ ) e $\alpha$-lactoalbumina $(14,4 \mathrm{kDa})$.

\section{Resultados e Discussão}

O maior GH obtido com o uso da papaína foi $28,17 \%$, nas condições de hidrólise pH 6,5, E:S 1:150, tempo de hidrólise de 5 horas e temperatura de $50^{\circ} \mathrm{C}$ (Tabela 1 ).

O gráfico de Pareto representa os efeitos estimados das variáveis e de suas interações sobre o grau de hidrólise, em ordem decrescente de magnitude (Figura 1). O comprimento de cada barra é proporcional ao efeito padronizado. A linha vertical é usada para julgar quais efeitos são estatisticamente significativos (Bruns et al., 2006).

A única variável principal que apresentou efeito significativo com o uso de papaína foi a relação E:S, com efeito negativo, ou seja, as menores relações E:S (1:150) favoreceram o GH. Esse resultado indica que deve haver um equilíbrio entre a concentração da enzima e do substrato para que a hidrólise seja eficiente, mas não excessiva.

Tabela 1. Grau de hidrólise da caseína do leite de cabra da raça Moxotó em função das variáveis $\mathrm{pH}$, temperatura, tempo de reação e relação enzima:substrato $(\mathrm{E}: \mathrm{S})$, com utilização da papaína como enzima proteolítica.

\begin{tabular}{|c|c|c|c|c|c|}
\hline Hidrolisado $^{(1)}$ & $\mathrm{pH}$ & $\begin{array}{c}\text { Temperatura } \\
\left({ }^{\circ} \mathrm{C}\right)\end{array}$ & $\begin{array}{l}\text { Tempo } \\
\text { (h) }\end{array}$ & E:S & $\begin{array}{c}\text { Grau de hidrólise } \\
(\%)\end{array}$ \\
\hline 1 & 6,5 & 40 & 1 & $1: 150$ & 14,85 \\
\hline 2 & 7,5 & 40 & 1 & $1: 150$ & 14,62 \\
\hline 3 & 6,5 & 50 & 1 & $1: 150$ & 13,47 \\
\hline 4 & 7,5 & 50 & 1 & $1: 150$ & 21,51 \\
\hline 5 & 6,5 & 40 & 5 & $1: 150$ & 20,94 \\
\hline 6 & 7,5 & 40 & 5 & $1: 150$ & 23,69 \\
\hline 7 & 6,5 & 50 & 5 & $1: 150$ & 28,17 \\
\hline 8 & 7,5 & 50 & 5 & $1: 150$ & 17,32 \\
\hline 9 & 6,5 & 40 & 1 & $1: 100$ & 20,30 \\
\hline 10 & 7,5 & 40 & 1 & $1: 100$ & 10,89 \\
\hline 11 & 6,5 & 50 & 1 & $1: 100$ & 9,11 \\
\hline 12 & 7,5 & 50 & 1 & $1: 100$ & 19,62 \\
\hline 13 & 6,5 & 40 & 5 & $1: 100$ & 6,24 \\
\hline 14 & 7,5 & 40 & 5 & $1: 100$ & 13,19 \\
\hline 15 & 6,5 & 50 & 5 & $1: 100$ & 15,54 \\
\hline 16 & 7,5 & 50 & 5 & $1: 100$ & 13,53 \\
\hline $17(\mathrm{C})$ & 7,0 & 45 & 3 & $1: 125$ & 24,67 \\
\hline $18(\mathrm{C})$ & 7,0 & 45 & 3 & $1: 125$ & 26,73 \\
\hline $19(\mathrm{C})$ & 7,0 & 45 & 3 & $1: 125$ & 23,17 \\
\hline $20(\mathrm{C})$ & 7,0 & 45 & 3 & $1: 125$ & 24,67 \\
\hline
\end{tabular}

${ }^{(1)}$ Hidrolisados resultantes de dois níveis das variáveis avaliadas e do ponto central (C).

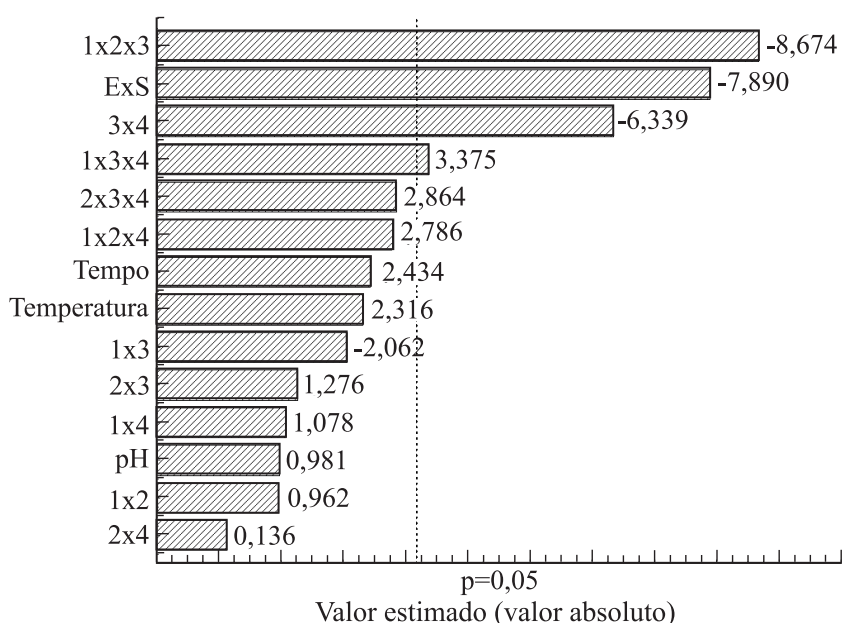

Figura 1. Gráfico de Pareto dos efeitos principais das variáveis $\mathrm{pH}$, temperatura, tempo de reação e relação enzima:substrato na hidrólise da caseína do leite de cabra da raça Moxotó com papaína, tendo como variável-resposta o grau de hidrólise. 1, pH; 2, temperatura da hidrólise; 3 , tempo de duração da hidrólise; e 4, relação enzima:substrato E:S. 
Resultado semelhante foi encontrado por Morais et al. (2002), que relataram a influência da relação E:S sobre a hidrólise da caseína bovina com uso de papaína, e observaram que a alteração da relação E:S de 2 para 4\% alterou significativamente o conteúdo de todas as frações cromatográficas, e produziu um perfil peptídico diferente, com diminuição dos níveis de di- e tripeptídeos e aumento do teor de aminoácidos livres e de peptídeos médios. $\mathrm{O}$ aumento da relação E:S deveria promover a quebra dos grandes e médios peptídeos a di- e tripeptídeos, porém levou à clivagem desses a aminoácidos livres. $\mathrm{O}$ pH, a temperatura e o tempo de reação apresentaram interação significativa para o GH da caseína caprina pela papaína.

O trabalho realizado por Cavalli et al. (2008) mostrou que a digestão do caseinato de sódio do leite de cabra, hidrolisado com peptidases aspárticas de extrato de flores Silybum marianum, a pH 6,5, foi observada após 1 hora. Porém, a digestão torna-se mais intensa com o decorrer do tempo de reação, sendo a $\beta$-caseína caprina degradada em $40 \%$, enquanto a $\alpha_{\mathrm{s} 1}$-caseína em $68 \%$, após 24 horas de incubação. Os resultados do presente trabalho corroboram os encontrados por esses autores, com o maior GH obtido com uso do mesmo $\mathrm{pH}(6,5)$ em maior tempo de hidrólise. Carreira et al. (2003) recomendam que a duração da reação hidrolítica não seja superior a 5 horas, porque este tempo pode favorecer a contaminação microbiana das preparações proteicas. Além disso, na obtenção dos hidrolisados enzimáticos, deve-se levar em consideração a relação custo-benefício da aplicação em escala industrial.

Com o uso de tripsina, observou-se que o maior valor de $\mathrm{GH}(29,55 \%)$ foi obtido a pH 8,5, com a relação E:S 1:150, durante 5 horas, à temperatura de $40^{\circ} \mathrm{C}$ (Tabela 2). Esses resultados corroboram os obtidos por Qi et al. (2003) que, ao utilizar a tripsina para hidrólise da caseína, mostraram que o GH aumentou de 5 para $15 \%$ quando o tempo de hidrólise aumentou de 9 minutos para 1 hora e 30 minutos, na temperatura de $40^{\circ} \mathrm{C}$. Porém, Morato et al. (2000) mostraram que não houve vantagem na ação da tripsina sobre a hidrólise da caseína, quando o tempo de hidrólise foi aumentado de 2 horas e 30 minutos para 4 horas e 55 minutos, pois a produção de pequenos peptídeos não foi aumentada nesse caso.

$\mathrm{O}$ único efeito significativo sobre o GH da caseína caprina, pela tripsina, foi a interação entre as variáveis pH e relação E:S, como pode ser observado na Figura 2. Observou-se que essa interação apresentou efeito negativo sobre o $\mathrm{GH}$, deste modo, quando o $\mathrm{pH}$ aumentou para 8,5 e a relação E:S diminuiu para 1:150 o GH foi favorecido. Schuchert-Shi \& Hauser (2009), ao trabalhar com tripsina, observaram que uma alta

Tabela 2. Grau de hidrólise da caseína do leite de cabra da raça Moxotó em função das variáveis $\mathrm{pH}$, temperatura, tempo de reação e relação enzima:substrato $(\mathrm{E}: \mathrm{S})$, com utilização da tripsina como enzima proteolítica.

\begin{tabular}{lccccc}
\hline Hidrolisado $^{(1)}$ & $\mathrm{pH}$ & $\begin{array}{c}\text { Temperatura } \\
\left({ }^{\circ} \mathrm{C}\right)\end{array}$ & $\begin{array}{c}\text { Tempo } \\
(\mathrm{h})\end{array}$ & $\mathrm{E}: \mathrm{S}$ & $\begin{array}{c}\text { Grau de hidrólise } \\
(\%)\end{array}$ \\
\hline 1 & 7,5 & 40 & 1 & $1: 150$ & 21,62 \\
2 & 8,5 & 40 & 1 & $1: 150$ & 25,01 \\
3 & 7,5 & 50 & 1 & $1: 150$ & 21,91 \\
4 & 8,5 & 50 & 1 & $1: 150$ & 21,97 \\
5 & 7,5 & 40 & 5 & $1: 150$ & 15,25 \\
6 & 8,5 & 40 & 5 & $1: 150$ & 29,55 \\
7 & 7,5 & 50 & 5 & $1: 150$ & 24,67 \\
8 & 8,5 & 50 & 5 & $1: 150$ & 25,36 \\
9 & 7,5 & 40 & 1 & $1: 100$ & 26,91 \\
10 & 8,5 & 40 & 1 & $1: 100$ & 23,69 \\
11 & 7,5 & 50 & 1 & $1: 100$ & 25,70 \\
12 & 8,5 & 50 & 1 & $1: 100$ & 12,96 \\
13 & 7,5 & 40 & 5 & $1: 100$ & 25,47 \\
14 & 8,5 & 40 & 5 & $1: 100$ & 17,67 \\
15 & 7,5 & 50 & 5 & $1: 100$ & 20,65 \\
16 & 8,5 & 50 & 5 & $1: 100$ & 16,29 \\
17 (C) & 8,0 & 45 & 3 & $1: 125$ & 16,23 \\
18 (C) & 8,0 & 45 & 3 & $1: 125$ & 21,34 \\
19 (C) & 8,0 & 45 & 3 & $1: 125$ & 17,09 \\
20 (C) & 8,0 & 45 & 3 & $1: 125$ & 17,95 \\
\hline
\end{tabular}

${ }^{(1)}$ Hidrolisados resultantes de dois níveis das variáveis avaliadas e do ponto central $(\mathrm{C})$.

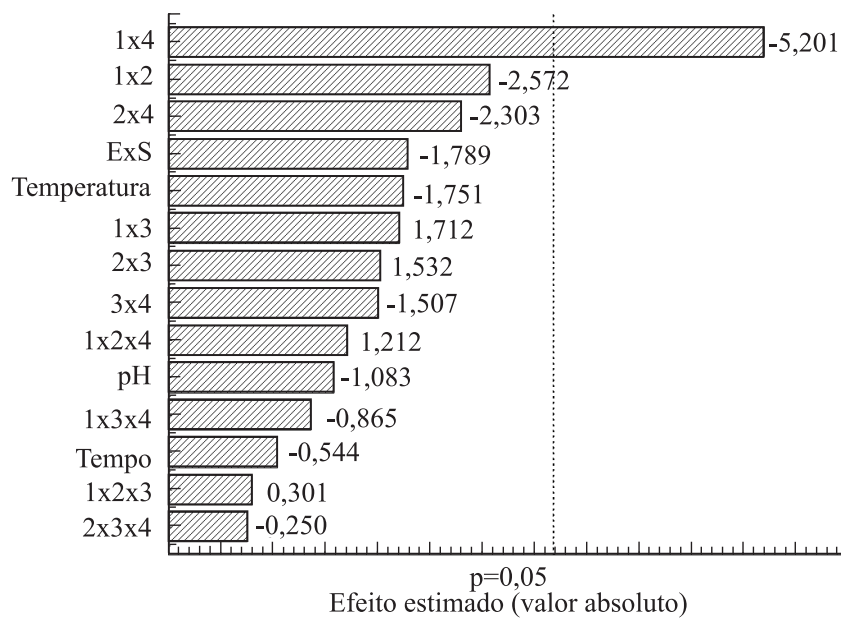

Figura 2. Gráfico de Pareto dos efeitos principais das variáveis $\mathrm{pH}$, temperatura, tempo de reação e relação enzima:substrato na hidrólise da caseína do leite de cabra da raça Moxotó com tripsina, que tem como variável-resposta o grau de hidrólise. 1, pH; 2, temperatura da hidrólise; 3, tempo de duração da hidrólise; e 4, relação enzima:substrato E:S. 
concentração de tripsina não favoreceu a hidrólise das proteínas citocromo c e mioglobulina.

Os resultados obtidos com a hidrólise da caseína caprina pela enzima pepsina estão apresentados na Tabela 3. O maior valor de GH $(38,27 \%)$ foi obtido nas condições de relação E:S 1:100, pH 3,0, durante 5 horas de hidrólise, a $40^{\circ} \mathrm{C}$. A análise estatística dos resultados mostrou que os efeitos $\mathrm{pH}$ e tempo, foram positivos e significativos para a hidrólise da caseína caprina com uso da pepsina (Figura 3). Dessa forma, o aumento nos níveis dessas variáveis favoreceu o GH. O pH 3,0, mais elevado, pode ter favorecido a hidrólise enzimática, já que a eficiência do sítio ativo das enzimas é dependente do $\mathrm{pH}$. O maior tempo de hidrólise (5h) também pode ter favorecido o aumento no grau de hidrólise por proporcionar maior duração da reação. Nota-se, ainda, que os dois melhores resultados do GH da caseína caprina também foram alcançados nas condições de $\mathrm{pH}$ 3,0 e durante 5 horas de hidrólise. Estes efeitos correspondem aos valores de GH de 38,27 e $37,53 \%$ (Tabela 3 ).

Tabela 3. Grau de hidrólise da caseína do leite de cabra da raça Moxotó em função das variáveis $\mathrm{pH}$, temperatura, tempo de reação e relação enzima:substrato (E:S), com utilização da pepsina como enzima proteolítica.

\begin{tabular}{lccccc}
\hline Hidrolisado $^{(1)}$ & $\mathrm{pH}$ & $\begin{array}{c}\text { Temperatura } \\
\left({ }^{\circ} \mathrm{C}\right)\end{array}$ & $\begin{array}{c}\text { Tempo } \\
(\mathrm{h})\end{array}$ & $\begin{array}{c}\mathrm{E}: \mathrm{S} \\
\text { Grau de hidrólise } \\
(\%)\end{array}$ \\
\hline 1 & 2,0 & 40 & 1 & $1: 150$ & 4,98 \\
2 & 3,0 & 40 & 1 & $1: 150$ & 9,63 \\
3 & 2,0 & 50 & 1 & $1: 150$ & 5,90 \\
4 & 3,0 & 50 & 1 & $1: 150$ & 25,24 \\
5 & 2,0 & 40 & 5 & $1: 150$ & 25,53 \\
6 & 3,0 & 40 & 5 & $1: 150$ & 17,49 \\
7 & 2,0 & 50 & 5 & $1: 150$ & 10,03 \\
8 & 3,0 & 50 & 5 & $1: 150$ & 37,53 \\
9 & 2,0 & 40 & 1 & $1: 100$ & 4,23 \\
10 & 3,0 & 40 & 1 & $1: 100$ & 27,42 \\
11 & 2,0 & 50 & 1 & $1: 100$ & 10,49 \\
12 & 3,0 & 50 & 1 & $1: 100$ & 19,90 \\
13 & 2,0 & 40 & 5 & $1: 100$ & 21,34 \\
14 & 3,0 & 40 & 5 & $1: 100$ & 38,27 \\
15 & 2,0 & 50 & 5 & $1: 100$ & 15,65 \\
16 & 3,0 & 50 & 5 & $1: 100$ & 32,93 \\
17 (C) & 2,5 & 45 & 3 & $1: 125$ & 17,20 \\
18 (C) & 2,5 & 45 & 3 & $1: 125$ & 28,57 \\
19 (C) & 2,5 & 45 & 3 & $1: 125$ & 25,07 \\
$20(\mathrm{C})$ & 2,5 & 45 & 3 & $1: 125$ & 27,42 \\
\hline
\end{tabular}

${ }^{(1)}$ Hidrolisados resultantes de dois níveis das variáveis avaliadas e do ponto central (C).
Os resultados apresentados por Carreira et al. (2003), que utilizaram a pepsina na hidrólise da caseína, mostraram que o emprego da temperatura a $40^{\circ} \mathrm{C}$ apresenta vantagem para a hidrólise, pois provoca redução dos teores de grandes peptídeos. Os resultados observados por Guo et al. (2009) demonstraram que o melhor GH da caseína ocorre quando uma maior quantidade de protease é adicionada, uma vez que o GH aumentou de 3 para $63 \%$, quando a relação E:S foi aumentada de 0,2 para $1,2(\% \mathrm{~m} / \mathrm{m})$. O trabalho realizado por Li et al. (2010), por sua vez, mostrou que quando a relação E:S aumentou de 0,1 para 0,2 $\mathrm{mL} 100 \mathrm{~mL}^{-1}$, o GH aumentou de 27,7 para $43,1 \%$. Este trabalho corrobora os resultados encontrados nos três trabalhos acima citados, no que se refere à temperatura empregada e à relação $\mathrm{E}: \mathrm{S}$ para o maior $\mathrm{GH}$ da caseína caprina obtido com a utilização da pepsina.

O perfil da hidrólise foi avaliado por SDS-PAGE (Figura 4). Na linha 7 pode ser observado o perfil das frações $\alpha_{s 1}, \beta$ e $\kappa$-caseína do leite de cabra da raça Moxotó. As frações $\alpha_{s 1}$ e $\beta$-caseína apresentaram massas molares superiores a $30 \mathrm{kDa}$. Resultados semelhantes da migração eletroforética foram apresentados por Egito et al. (2006), os quais descrevem também a visualização de uma banda mais intensa da $\beta$-caseína no leite de cabra. A fração da $\beta$-caseína corresponde

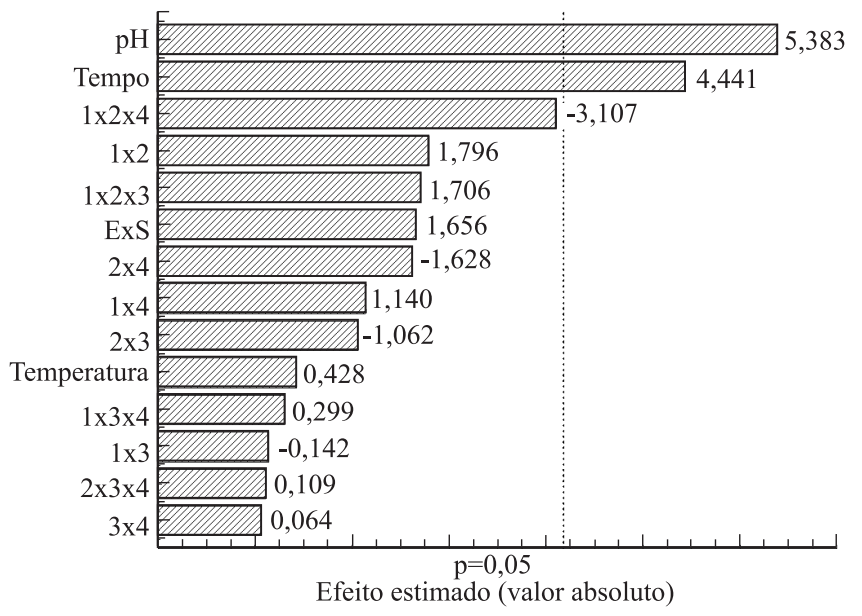

Figura 3. Gráfico de Pareto dos efeitos principais das variáveis $\mathrm{pH}$, temperatura, tempo de reação e relação enzima:substrato na hidrólise da caseína do leite de cabra da raça Moxotó com pepsina, que tem como variável-resposta o grau de hidrólise. 1, pH; 2, temperatura da hidrólise; 3, tempo de duração da hidrólise; e 4, relação enzima:substrato $\mathrm{E}: \mathrm{S}$. 
a aproximadamente $60 \%$ da caseína caprina (Trujillo et al., 1997).

A eletroforese SDS-PAGE das amostras correspondentes aos menores e maiores graus de hidrólise da caseína caprina obtidos com utilização da pepsina, tripsina e papaína estão representadas pelas linhas 1 a 6 da Figura 4. As linhas 1 e 2 apresentam hidrolisados da caseína caprina com a pepsina, com $\mathrm{GH}$ correspondentes a 4,23 e 38,27\% dos ensaios 9 e 14 da Tabela 3. As linhas 3 e 4 apresentam os hidrolisados da caseína caprina que utilizaram a tripsina, que corresponderam aos GH 12,96 e 29,55\% dos ensaios 12 e 6 da Tabela 2, respectivamente. As linhas 5 e 6, por sua vez, referem-se aos hidrolisados da caseína caprina obtidos pela papaína, com GH de 6,24 e 28,17\% dos ensaios 13 e 7 da Tabela 1. Não foi possível diferenciar visualmente os graus de hidrólise para a pepsina e tripsina, pois tanto

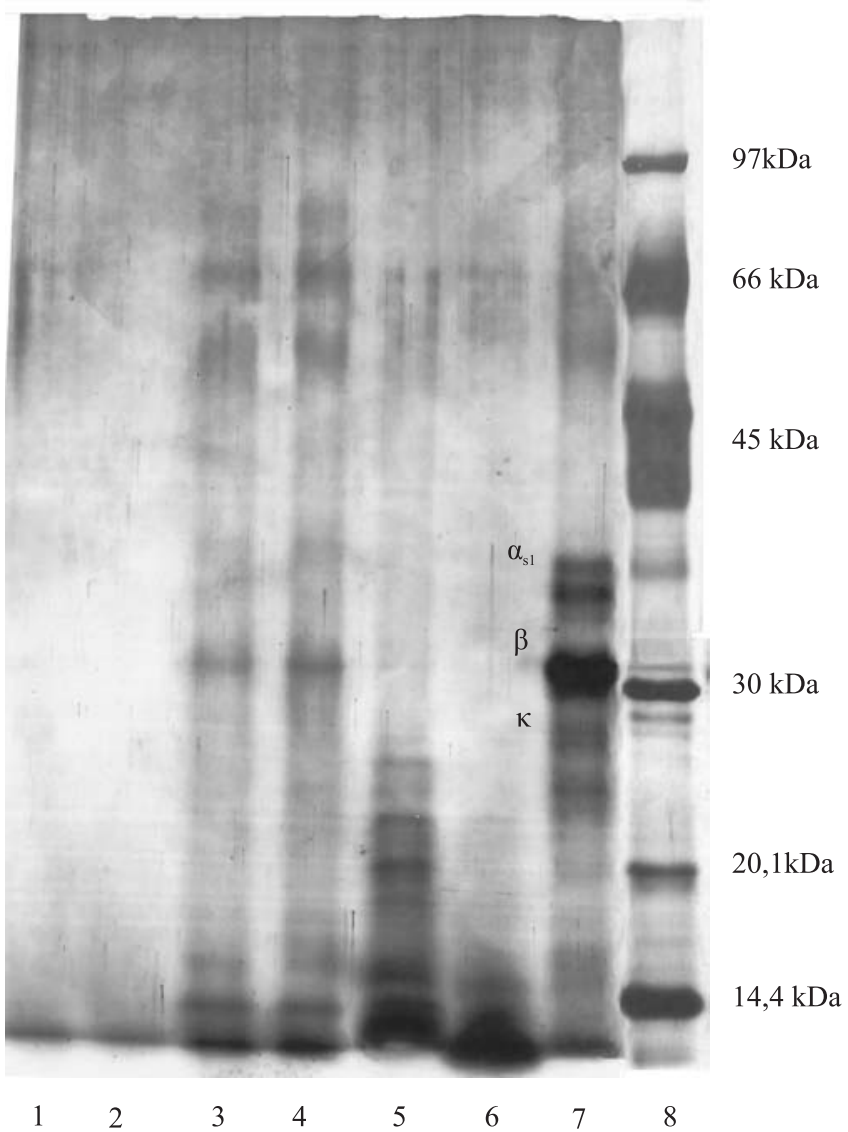

Figura 4. SDS-PAGE (coloração por prata) dos hidrolisados com pepsina ( 1 e 2), tripsina (3 e 4), e papaína (5 e 6). 7, caseína do leite de cabra da raça Moxotó; 8, padrão de massa molar. o maior como o menor grau de hidrólise apresentam perfis eletroforéticos semelhantes, ao passo que foi possível diferenciar eletroforeticamente o menor e o maior grau de hidrólise da papaína. Porém é nítida a diferença entre as três enzimas utilizadas.

Os produtos da hidrólise da caseína caprina caracterizados pelo SDS-PAGE apresentaram massas molares relativas menores de $30 \mathrm{kDa}$. Esses resultados corroboram os apresentados por Trujillo et al. (1997), que observaram bandas proteicas resultantes da hidrólise da caseína pela quimosina. Esses autores também observaram bandas com massas molares correspondentes a $14,5 \mathrm{kDa}$, as quais são equivalentes a para- $\kappa$-caseína, sendo que os outros peptídeos podem ter sido derivados da $\alpha_{s-}$ caseína.

A hidrólise da caseína caprina com a pepsina levou à obtenção apenas de hidrolisados com massas molares inferiores a $14,4 \mathrm{kDa}$, o que demonstra a eficiência dessa enzima para hidrólise da $\alpha_{s 1}, \beta$ e $\kappa$-caseína. Soares et al. (2004) relataram que os hidrolisados proteicos de melhor qualidade devem apresentar elevados teores de dipeptídeos e tripeptídeos, assim como de peptídeos com massa molar média de 500 Da. Além disso, devem conter baixos teores de aminoácidos livres e de peptídeos com massa molar superior a $800 \mathrm{Da}$.

Ao analisar o perfil dos hidrolisados com menor e maior GH da caseína caprina obtidos com a utilização da tripsina, observa-se que essa enzima não promoveu a clivagem completa da $\beta$-caseína, mas hidrolisou $\alpha_{\mathrm{s} 1}$ e $\kappa$-caseína caprina. Contudo, a papaína hidrolisou $\alpha_{\mathrm{s} 1}$ e $\beta$-caseína caprina, porém não promoveu a clivagem completa da $\kappa$-caseína.

\section{Conclusões}

1. As melhores condições de hidrólise da caseína do leite de cabra Moxotó são obtidas com a pepsina, em pH 3,0, com relação E:S de 1:100 e 5 horas de hidrólise a $40^{\circ} \mathrm{C}$.

2. A hidrólise da caseína caprina é influenciada positivamente pelo $\mathrm{pH}$ e pelo tempo de hidrólise, com o uso da pepsina; observando-se interações significativas antagônicas entre $\mathrm{pH}$ e relação $\mathrm{E}: \mathrm{S}$, com o uso da tripsina; e entre $\mathrm{pH}$, temperatura e tempo de hidrólise, com o uso da papaína.

3.A pepsina apresenta elevada eficiência na hidrólise de $\alpha_{\mathrm{s} 1}, \beta$ e $\kappa$-caseína, evidenciada por hidrolisados com massa molar abaixo de $14,4 \mathrm{kDa}$. 


\section{Agradecimentos}

Ao Conselho Nacional de Desenvolvimento Científico e Tecnológico, Coordenação de Aperfeiçoamento de Pessoal de Nível Superior e à Faculdade São Miguel, pelo apoio financeiro.

\section{Referências}

BIASUTTI, E.A.R. Otimização das condições da hidrólise enzimática das proteínas do soro de leite para obter elevado teor de oligopeptídeos: utilização da subtilisina e da pancreatina. 2006. 88p. Dissertação (Mestrado) - Universidade Federal de Minas Gerais, Belo Horizonte.

BRASIL. Ministério da Agricultura, Pecuária e Abastecimento. Instrução Normativa № 37, de 31 de outubro de 2000. Aprova o regulamento técnico de identidade e qualidade do leite de cabra. Diário Oficial [da] República Federativa do Brasil, 08 nov. 2000. Seção 1, p.23.

BRUNS, R.E.; SCARMINIO, I.S.; BARROS NETO, B. de. Statistical design - chemometrics. Amsterdam: Elsevier, 2006. 412p.

CARREIRA, R.L.; SILVA, V.D.M.; MORAIS, H.A.; MOTTA, S. da; JUNQUEIRA, R.G.; SILVESTRE, M.P.C. Otimização da hidrólise da caseína para elevar o teor de pequenos peptídeos: emprego da pepsina. Ciência e Agrotecnologia, v.27, p.625-634, 2003.

CAVALli, S.V.; SILVA, S.V.; CIMINO, C.; MALCATA, F.X.; PRIOLO, N. Hydrolysis of caprine and ovine milk proteins, brought about by aspartic peptidases from Silybum marianum flowers. Food Chemistry, v.106, p.997-1003, 2008.

EGITO, A.S.; ROSINHA, G.M.S.; LAGUNA, L.E.; MICLO, L.; GIRARDER, J.M.; GAILLARD, J.L. Método eletroforético rápido para detecção da adulteração do leite caprino com leite bovino. Arquivo Brasileiro de Medicina Veterinária e Zootecnia, v.58, p.932-939, 2006.

FERNANDES, M.F.; QUEIROGA, R. de C.R. do E.; MEDEIROS, A.N. de; COSTA, R.G.; BOMFIM, M.A.D.; BRAGA, A.A. Características físico-químicas e perfil lipídico do leite de cabras mestiças Moxotó alimentadas com dietas suplementadas com óleo de semente de algodão ou de girassol. Revista Brasileira de Zootecnia, v.37, p.703-710, 2008.

GUO, Y; PAN, D.; TANOKURA, M. Optimisation of hydrolysis conditions for the production of the angiotensin-I converting enzyme (ACE) inhibitory peptides from whey protein using response surface methodology. Food Chemistry, v.114, p.328-333, 2009.

HORWITZ, W. (Ed.). Official methods of analysis of AOAC International. $17^{\text {th }}$ ed. Gaithersburg: AOAC International, 2000.

KRÜGER, C.C.H. Produção e caracterização química e fisiológica de caseinofosfopeptídeos de leite bovino. 2006. 149p. Tese (Doutorado) - Universidade Federal do Paraná, Curitiba.
LAEMMLI, U.K. Cleavage of structural proteins during the assembly of head of bacteriophage T4. Nature, v.227, p.680-685, 1970.

LÉONIL, J.; GAGNAIRE, V;; MOLLÉ, D.; PEZENNEC, S.; BOUHALLAB, S. Application of chromatography and mass spectrometry to the characterization of food proteins and derived peptides. Journal of Chromatography A, v.881, p.1-21, 2000.

LI, Z.Y.; YOURAVONG, W.; H-KITTIKUN, A. Protein hydrolysis by protease isolated from tuna spleen by membrane filtration: a comparative study with commercial proteases. LWT - Food Science and Technology, v.43, p.166-172, 2010.

LOWRY, O.H.; ROSEBROUGH, N.J.; FARR, A.L.; RANDALL, R.J. Protein measurement with the Folin phenol reagent. The Journal of Biological Chemistry, v.193, p.265-275, 1951.

MICHAELIDOU, A.M. Factors influencing nutritional and health profile of milk and milk products. Small Ruminant Research, v.79, p.42-50, 2008.

MORAIS, H.A.; BARBOSA, C.M. da S.; LOPES, D.C.F.; OLIVEIRA, M.C. de; SILVESTRE, M.P.C. Caracterização do perfil peptídico e de aminoácidos em hidrolisados da caseína. Archivos Latinoamericanos de Nutrición, v.52, n.1, 2002.

MORATO, A.F.; CARREIRA, R.L.; JUNQUEIRA, R.G.; SILVESTRE, M.P.C. Optimization of casein hydrolysis for obtaining high contents of small peptides: use of subtilisin and trypsin. Journal of Food Composition and Analysis, v.13, p.843-857, 2000.

OLALLA, M.; RUIZ-LÓPEZ, M.D.; NAVARRO, M.; ARTACHO, R.; CABRERA, C.; GIMÉNEZ, R.; RODRIGUEZ, C.; MINGORANCE, R. Nitrogen fractions of Andalusian goat milk compared to similar types of commercial milk. Food Chemistry, v.113, p.835-838, 2009.

OLIVEIRA, J.C.V. Caracterização e perfil etnológico de rebanhos caprinos nos Municípios de Ibimirim e Serra Talhada, Estado de Pernambuco. 2004. 58p. Dissertação (Mestrado) Universidade Federal Rural de Pernambuco, Recife.

PEZOA, V; SALAS-MELLADO, M.M. Obtenção de um concentrado de proteínas de pescado para alimentos, pelo método enzimático, utilizando as próprias enzimas do pescado. Rio Grande: Universidade Federal do Rio Grande, 1979.

QI, W.; HE, Z.; SHI, D. Product distribution of casein tryptic hydrolysis based on HPSEC analysis and molecular mechanism. Chemical Engineering Science, v.58, p.767-775, 2003.

ROCHA, L.L. da; BENÍCIO, R.C.; OLIVEIRA, J.C.V.; RIBEIRO, M.N.; DELGADO, J.V. Avaliação morfoestutural de caprinos da Raça Moxotó. Archivos de Zootecnia, v.56, p.483-488, 2007.

ROSSINI, K.; NOREÑA, C.P.Z.; CLADERA-OLIVERA, F.; BRANDELLI, A. Casein peptides with inhibitory activity on lipid oxidation in beef homogenates and mechanically deboned poultry meat. LWT - Food Science and Technology, v.42, p.862-867, 2009.

SANTILLO, A.; KELLY, A.L.; PALERMO, C.; SEVI, A.; ALBENZIO, M. Role of indigenous enzymes in proteolysis of casein in caprine milk. International Dairy Journal, v.19, p.655-660, 2009. 
SCHUCHERT-SHI, A.; HAUSER, P.C. Peptic and tryptic digestion of peptides and proteins monitored by capillary electrophoresis with contactless conductivity detection. Analytical Biochemistry, v.387, p.202-207, 2009.

SOARES, R. Del L.; SILVA, V.D.M.; LOPES, D.C.F.; JUNQUEIRA, R.G.; FIGUEIREDO, A.F. de S.; SILVESTRE, M.P.C. Perfil peptídico de hidrolisados enzimáticos de leite em pó desnatado. Revista Brasileira de Ciências Farmacêuticas, v.40, p.353-362, 2004.

STATSOFT. Statistica: data analysis software systems. Version 8.0. Tulsa: StatSoft, 2008.
SWITZER, R.C.; MERRIL, C.R.; SHIFRIN, S. Highly sensitive silver stain for detecting proteins and peptides in polyacrylamide gels. Analytical Biochemistry, v.98, p.231-237, 1979.

TRUJILlO, A.J.; GUAMIS, B.; CARRETERO, C. Proteolysis of goat casein by calf rennet. International Dairy Journal, v.7, p.579-588, 1997.

VARGHESE, G.; DIWAN, A.M. Simultaneous staining of proteins during polyacrylamide gel electrophoresis in acidic gels by countermigration of Coomassie brilliant blue R-250. Analytical Biochemistry, v.132, p.481-483, 1983.

Recebido em 4 de maio de 2010 e aprovado em 30 de julho de 2010 